\title{
The World Journal of Surgery Welcomes Professor Kathryn Chu to the Editorial Board
}

\author{
Julie Ann Sosa ${ }^{1}$
}

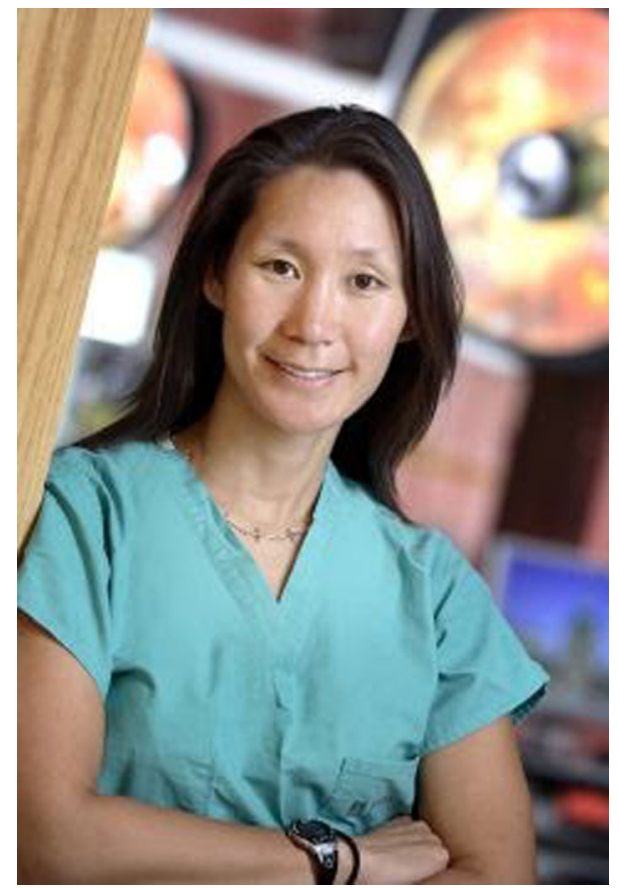

Kathryn Chu received her undergraduate degree from Stanford University and her medical degree from UCSF where she also completed her general surgery residency. She was a Fulbright Scholar to the UK and received a Masters in Public Health in Developing Countries from the London School of Hygiene and Tropical Medicine. She was a colorectal fellow at the Lahey Clinic and then joined the faculty at Johns Hopkins Medicine. Dr. Chu has worked in Africa full time since 2007. She completed 4 years with Medecins Sans Frontieres as a surgical advisor and epidemiologist and has worked for the University of Rwanda and the University of Cape Town as well as at several mission and government hospitals on the continent training local surgeons. She is currently the Director for the Centre for Global Surgery and Professor of Global Surgery at Stellenbosch University in South Africa. Her research focuses on equitable surgical access to safe and timely surgical care as well as humanitarian surgical delivery. She is the global surgery representative for the Association of the Surgeons of South Africa. She is the founder of AfroSurg, a southern African initiative to improve surgical access in the region and a member of the Southern African Development Community National Surgery Obstetric Anesthesia (NSOAP) Task Team and the South African NSOAP Task Team.

Publisher's Note Springer Nature remains neutral with regard to jurisdictional claims in published maps and institutional affiliations.

Julie Ann Sosa, MD, MA, FACS—Editor in Chief, World Journal of Surgery.

\footnotetext{
Julie Ann Sosa

julie.sosa@ucsf.edu
}

1 San Francisco, USA 